Asian Review of Social Sciences

ISSN: 2249-6319 Vol.7 No.1, 2018, pp. 35-39

(C) The Research Publication, www.trp.org.in

\title{
English Skills Learning Authority Dimension in History Learning
}

\author{
M. Suganya \\ Department of Education of English, Indra Ganesan College of Education, \\ Tiruchirappalli, Tamil Nadu, India \\ E-Mail: Suganya.kcas@gmail.com
}

\begin{abstract}
India Service of Instruction in light of the want of a dynamic and extraordinary in impacting the world forever an obligatory pass subject in constrain in 2013, is an acknowledgment to the legacy and fortunes of the country in keeping up the true realities and data to the age without bounds. In the audit of parts of the position of authority of educators in applying the exploration of history is incorporated on the Rationality of Training Instructors, which upgrade the instructing calling to maintain moral instructor grand, dynamic and logical disapproved, willing to maintain the desires of the nation and commended the nation's social legacy, guarantee the improvement of the individual and keep up a group that is joined together, fair, dynamic and restrained, bear the part of instructors as specialists of progress and initiative in training that started of the classroom through formal or casual training process stretches out past the school, group and nation. The concentration of this paper is an exchange on the part of educator authority impacts the adequacy of instructing and learning in the history classroom atmosphere that prompt instructors' recognitions about the part of instructor administration, initiative lessons, part of instructor authority and the position of authority of the successful instructor. There are discourses to underscore the parts of the variables that influence the atmosphere of the classroom, molding the plan classroom, execution strategies for powerful classroom, learning atmosphere appropriate for history, and additionally the obstructions and difficulties infers the adequacy of educators in the instructing and learning process.
\end{abstract}

Keywords: Educator initiative, authority lessons, powerful classroom, compelling

\section{INTRODUCTION}

On the issue of leadership roles in education, found a lot of research done on leadership [5] [15] compared to the leadership role of the teacher in the classroom. According Banathy [1] systemic change is the change that occurs in any part of the organization that affects the entire organization and beyond will bring new changes to the organization. When systemic change is associated with the role of teacher leadership, understanding the role of teacher leadership is a unit that will affect the overall effectiveness of a school. The differences in the performance of pupils in schools are also affected by the significant difference in self-teachers who contributed to the success of a school. In accordance with National Educational Philosophy aims to shape the development potential of individuals in a holistic and integrated way to produce students with a balanced and intellectually human. Therefore, understanding the importance of studying the historical theme and civilization of aspen water is a priority for the use of knowledge and the strengthening of the patriotic spirit that is nourished through Continuous learning in school.

\section{LITERATURE REVIEW}

\section{A. Review Stage}

In the study of the role of teachers leadership in the history of science integrated to the philosophy of teacher education, which enhance the teaching profession to promote professors of glorious, progressive and scientific virtueminded, ready to support the aspirations of the country and praise the country's cultural heritage, ensure the development of individuals and maintain a community of solidarity, democracy, progress and discipline, take on the role of teacher as the agent of change and leadership in education beginning in the classroom through formal or informal learning outside of school, community, and country [14]. Subject to peel the history of civilization of a nation and the fact that the country's cultural heritage must be preserved as a relic of the sovereign will of the nation's heritage. Today's generation is the catalyst of the future heir who will uphold the principles and direction of the country. In line with the National Education Philosophy which aims to shape the development potential of individuals in a holistic and integrated manner to produce a balanced and harmonious students intellectually, spiritually, emotionally and physically. Thus, understanding the importance of studying the subject of history as pillar of identity and civilization of the country is a priority in order to apply the knowledge and strengthen the patriotic spirit that is fostered through continuous learning in school.

\section{B. Teacher Leadership Role Definition}

Attempts [7] defines leadership as a business or actions affect others with no formal or informal basis for the purpose of achieving the desired goals. Good leadership will always bring positive change to the party led. Drath and Palus (in, Yukl, 2002) [20] said that the leadership is the process of accepting what others are doing together with the people will understand and be committed. Southworth [18], defining the role of teacher leadership is associated with teaching and learning, including learning the profession of teachers and student development. De Bevoise [7], also stressed that the leadership role of the teacher is any act committed by a principal or a third-party entrusted to promote the growth of learning among students. Therefore, 
teachers should take care of teaching and learning, including learning of his profession or the students themselves. Based on the definition above, leadership is the art or process of influencing human activities related to their duties and responsibilities which their involvement is voluntary and is working towards the effectiveness and the achievement of organizational goals. However, when the leadership discussed from the perspective of education, leadership is often associated with the role of teacher leadership in schools and classrooms.

Hook and Vass [10] defines the role of the classroom teacher leadership as a skill in which teachers use the leadership style of the skills themselves and communicate with others. In addition, this skill is the ability to link ongoing daily interaction with the two parties. This skill is also a teacher's ability to communicate the vision to the students and to convince and influence them. Leadership role of teachers exists in a state where the pupils acquire a piece of information or input that they do not expect to achieve in every classroom, or whenever there is a positive development that will directly affect their personality or when a teacher of hands of all students the classroom became silent; or whenever the pupils expect guidance from a teacher or role model. According to Hook and Vass [10], effective leadership role guruyang need teachers who have skills that include, can develop the ability to understand and have a vision; have resulted in an effective relationship skills; understand the behavior and wishes of his disciples; understand the classroom is a system; and ability to find solutions and analyze information.

In order to produce effective teaching, Fenstermacher and Soltis [8] suggested three approaches, namely executive; Empathy approach; and the Liberal approach. Teaching and learning process normally takes place in the classroom where students who follow the teachings of the respondents and teachers act as leader. Meaningful learning is always linked with the quality of teacher leadership roles whether successful push; act as a reference; and capable of affecting the students to strive to achieve an objective such as learning objectives. Implementation can be accomplished during the process of teaching and learning in the classroom by referring to efforts geared towards the achievement of learning outcomes by topic. Teacher success as a leader will prevail in its ability to make changes in the classroom through collaboration with students to achieve the objectives of teaching and learning. The role of teacher leadership is also associated with people who are capable of planning, directing, controlling the course of the process and develops strategies for achieving the goal. Therefore, leaders must be able and capable to change the thinking behavior or attitude subordinated to push towards achieving the goal.

\section{Teachers' Perceptions on the Role of Teacher Leadership}

Synonymously teachers have the perception that the leadership role of the teacher lies with the school principal or administrator. According to Blasé and Blase [2] foundation for the success of a school instructional leaders rather than caused by the principals or headmasters but is encouraged by the coordination and collaboration of teachers and principals as instructional leaders are as coordinator or administrator.

Teachers thought that their role is to teach students in accordance with the syllabus prepared and technically to ensure that the syllabus provided must be spent in accordance with the stipulated time frame. Sparks [19] argues that teachers are agents of change are important in ensuring their school into an effective school.

The general goal of the leadership role of the teacher is to add value (Value added) or maintain the conditions that promote student learning atmosphere. Skills and leadership roles of teachers who practiced a school administrator should be no term partnership with or delegated to teachers involved in teaching and learning. Besides that, the school administration must take the lead teacher for excellence in teaching programs and learning, Among them, the issue of teaching and management, which includes evaluation of teachers and students, school climate, curriculum and cocurriculum, resources and teaching equipment, staff, decision-making, the goals of teaching short / long term, community support, communication and interaction between principals as school administrators and teachers should be given the necessary skills.

Studies show that in the process of leading the teaching programs, the role of teachers as engineering leadership roles need efficiency of education and academic excellence that can be implemented in the form of an effective strategy. Due to the various aspects of education are not static and often changing as increasingly complex education program; increased professionalism and specialization of teachers; the introduction of educational technology as a source of teaching and learning methods; community and parental expectations; and changes in the curriculum. This all will create new pressures and demands should be taken into account in the realization of the role of teacher leadership.

\section{METHODOLOGY}

Researcher used narrative literature to describe the current state of both art and science in the focus of this study. Researchers used a literary narrative research to build the foundation of scientific knowledge. Researcher collected all the important points in the discussion, and put them in here with reference to the particular field in which this paper was originally based.

\section{FINDINGS}

Today, people understand the importance of history, both from a global perspective and in terms of our everyday lives. The days when history was considered a lifeless, irrelevant subject are long gone. History is about who we 
are and where we came from, and when it comes to bringing the past alive, History teachers are the perfect leader tools for the job.

\section{A. Leadership Role of Teachers Features}

According Shippen and Shippen [16], a teacher who has effective leadership has seven leadership that can build and deliver a clear vision in the classroom [3], has the ability to lead and flexibility as well as transparency [22], ability to lead and be an example and an exemplary role model to his students, intelligently and efficiently make decisions beneficial to students with no prejudice to the interests of the organization [4], scraping selfishness instead prioritize the interests and welfare of pupils students [16] although sometimes bring trouble to himself, making a balanced judgment and rational aims to avoid the feeling of dissatisfaction among students, be honest and humble for the purpose of building a positive relationship between teachers and student transparent [22], and try to practice continuous learning for the purpose of enhancing and increasing their knowledge and skills. According to Kane [11], knowledge gained by teachers for continuing education will increase the effectiveness of their teaching in the classroom. The impact, the teaching and learning situation in the classroom to be more realistic, systematic and controlled manner.

Lashway [13], discussed the leadership role of the teacher to generate the effectiveness of the teaching and learning of Leading Learning Communities program developed by the National Association of Elementary School Principals (ESP). ESP has redefined the role of teacher leadership to generate the effectiveness of teaching and learning; to encourage the students to prioritize efforts to learn; determine the expectations of high achievement; adjust the content of teaching and learning towards the standard standards; using a variety of data sources to assess learning; and enable the support of the community or stakeholders stakeholders for the success of the school.

\section{B. Factors Affecting the Classroom Climate}

Hook and Vass [10], had referred the culture of the classroom effective way to identify some of the factors that affect the climate of the classroom; find a balance between encouragement and warning, develop rapport with students; involve students with aspirations and expectations; maintain perfect working relationship, practicing how to make a choice which means; assure the safety factor and confidence; putting pupils as part of the classroom; focus on the good things that were done; and teacher skills..

\section{Effective Teaching Leaders}

Glickman [24] pointed out that the leadership role of the teacher will be able to run efficiently if the leader has three main categories, namely the need to acquire knowledge of the area; tasks and responsibilities; and the need to practice the skills and expertise.

A teacher who teaches the History subject compulsorily dominate deep knowledge in this field to ensure that the learning process is carried out smoothly. When students ask questions, teachers can give a positive response and meet the needs of students who want to know where students can cultivate self-confidence. When giving assignments to students, teachers should emphasize the goals of each assignment and students should also understand the procedures invitation gain knowledge of self-discovery. Leadership role of teachers in the classroom requires skill which covers two aspects, namely intrapersonal and interpersonal skills as well as technical skills [6]. Intrapersonal and interpersonal skills is an attempt to guess the mood, goals, motivations and feelings when faced with their students in the learning process. Teachers who use and master these skills will successfully master the students and the teaching and learning environment in the classroom. Teachers in the classroom should be sensitive to facial expressions, voice and movement of the limbs students. Abilities and concerns of teachers recognize and identify the nature of the students in the classroom allows inculcate a culture of student interest learn and explore the particular subject of history that emphasizes memorization of facts and warnings as well. In addition, the History Teachers need to master ICT skills including management and technical teaching aids such as computers, LCD projectors, video, charts, and so on for the teaching and learning process more berintraktif and diversity[12]. At the same time teachers can use the form, material circulation and newspaper clippings to carry out the teaching and learning process more conducive and challenging.

According to a study by Porter and Brophy [25] to lesson, there are seven key determinants of effective teachers; can achieve academic and socialization, has a mastery of content and in-depth knowledge, a clear and detailed; to model and to train students to process information; correcting misconceptions sound understanding of the facts or content among students; expand student experiences and mendambarkan yourself as a reflective teacher.

\section{Shaping the Agenda Classroom}

Agenda classroom is very important to determine the implementation plan the role of teacher leadership. It will establish a classroom climate that is conducive to academic and social development of pupils. According to Hook and Vass [10] there are four main keys in the classroom agenda of rights, responsibilities, rules and routines. When applying leadership theories in the classroom, teachers require a clear response, which can be delivered, which framed to make a decision on student behavior. It is a framework that can be accepted and understood by the students in a particular situation. The decision should be based on considerations that had been agreed upon and adhered to in terms of the four basic rights of students; students' rights to learn; the 
rights of teachers to teach; the right of every individual to security aspects, both physically and psychologically; and the right of every individual to the level of respect and veneration.

Based on these rights, management of behavior in the classroom is an absolute right of teachers to overcome confusion in the classroom. In the meantime, teachers can meet professional responsibilities as authorities on the protection of individual rights in the security aspect. Students must feel good and secure before undergoing the learning process. Rights and responsibilities are the two things are inseparable. Responsibilities of the role of teacher leadership focuses on the behavior of students to make decisions or elections positively[23]. As a teacher, an effort to encourage students to choose responsible behavior towards an effective leadership role of teachers is complicated. Teachers should encourage students to be responsible for the treatment and efforts to attain the desired success. At school, we always emphasize the importance of regulation and law school. During the process of teaching and learning, we need to emphasize the regulations which must be observed by students to ensure that teaching and a learning process on track[17]. Teachers must distinguish between rules and routines.

The first rule, ensure that teachers can teach and students can learn in a conducive atmosphere. Here the responsibility of the leadership role of the teacher will give a briefing on the rules in the first meeting with the students that touch on aspects; talk or whisper regulation, in response to questions, the teacher out of the classroom, distribution of books and teaching materials, lesson start and end of the lesson, to ensure that they abide by the pre-given rules. Second, set that will guarantee the physical and psychological safety of school property. Third, to protect the rights of honor and glory. The three rules are a guide for teachers to ensure that students understand and comply with the regulations enacted by the school[6]. Different routine with emphasis on rules for routine administration and the necessary procedures so that the classroom atmosphere is well managed. Routine is a set of behaviors that need to be implemented to help the success of students[12]. In addition, referring to the classroom routine classroom activities such as marking the arrival of the students schedule, check the physical condition of the classroom or laboratory, distribute teaching materials, collect and return the exercise books and so on.

\section{E. The Skills Required}

Appropriate climate for learning can be generated when the teacher can ensure there is an appropriate environment to allow the learning process to run smoothly [23]. In this context, the mission pengarapan class and students should be clear and easy to understand. Teachers must have a role as helping to promote the classroom as a place for academic learning, in addition to performing the following things: Emphasis on Basic Teaching; Teacher expectations that all students are capable of achieving excellence by National Education Philosophy; The existence of a system of clear learning objectives to monitor student performance; and implement the teaching of history in an effective, systematic and have uniqueness when studying.

In the process of teaching and learning of History, teacher must act to reflect on themselves before, during and after each lesson. Before the lesson, the teacher must create a reflection of the plan and is ready to start teaching. During the teaching process the teacher must act to maximize the knowledge and methods of delivering effective in capturing the mood, atmosphere and interactive two-way with students. After the lesson, the teacher reflex what he had done, spoken and rigged in classroom [20]. Subject teachers are encouraged to write a diary on the history of reflex for future reference and repair errors. During the learning process is carried out, the teacher can practice collaborative learning.

This means that students in a state of positive and selfreliance, responsibility, teamwork and mingle with members of the group to carry out specific tasks. Next, the students think of the problem that is addressed to him. Teachers also appear necessary to define appropriate learning objectives and determining the size of such groupsheterogeneous group patterned allows each member has a specific role. In order to find a solution, between a group of students discussing it necessary, carry out experimental session and seek a referral either from medium teachers, books or the internet. In this context, the teacher as an observer and facilitator of student learning process and evaluate the results of their work [20] [23]. With the approach, students have the opportunity to develop their abilities and self-confidence, especially in the exploration of its fact-finding or order of any discoveries and activities. At the end of the session, the teacher must give praise and support and reward the effort shown by students in their engagement in active learning process and manipulate classroom space as a source of effective interaction.

\section{CONCLUSION}

Ministry of Education and Ministry of Higher Education Penagajian difficult to supply projections consistently History teacher recruitment based on current needs and movement history teacher who taught not in accordance with the request of the school administrators option. The problem arises when there is a demand and a shortage of teachers; teachers who do not have the option appropriate to teach specific subjects; large class sizes; History option interview candidates ineligible, and so on. This shortage is a constraint to the school principal to perform the role of teacher leadership roles. This issue has caused them to be confused about the appropriate way to enhance the leadership role of responsibility as an effective teacher. The implication, some of the principals cannot motivate teachers towards excellence and effectiveness of teaching and learning. 
School education is an organizational unit for which teachers should be involved in aspects of the leadership role of the teacher in addition to educational leadership. Adhering to the theory, teaching is the teacher's responsibility to ensure all the energy and efforts towards the achievement of an effective educational program. This responsibility includes holding the goals and objectives of teaching and learning, and guide students so that their efficiency in learning and other areas of the curriculum can be improved. Responsibility of the teacher as well as an emphasis on the achievement of the objectives matlamat and learning, decision making, organizing events and working with other teachers so that the goal is reached.

Study of Hallinger et al., [9] that shows the features found on a school actually had a profound impact should be taken into account in forming a leadership role model of a successful teacher. The role of teacher leadership practiced by teachers not only can determine the achievement of a classroom but also have an impact on all individuals in the classroom. Teachers should not include reflection canned; trying to implement collaborative learning and problem solving in the direction guruyang establish effective leadership role.

\section{REFERENCES}

[1] P. Hallinger, J. Murphy, M. Well, R. P. Mesa, and A. Mitman, "School effectiveness: Identifying the specific practices, behaviors for principals”, NASSPBulletin, Vol. 67, No. 463, pp. 83-91, 1983.

[2] L. Cuban, "Transforming the frog into a prince: Effective school research, policy and practice at the district level", Harvard Education Review, Vol. 54, No.2, pp. 129-151, 1984.

[3] W. De Bevoise, "Synthesis of research on the principal as instructional leader”, Educational Leadership, Vol. 41, pp. 14-20, 1984.

[4] Porter and Brophy, "Effective teaching - Education Development Trust”, Educational Leadership, Vol. 45, No. 8, pp. 74-85, 1988.

[5] Glickman and Bey, Supervision in Handbook of research on teacher education, London: Charles E. Merrill Publishing Co, 1990.
[6] W. Smith and R. Andrews, Instructional leadership: How principals make a difference, Alexandria, VA: ASCM, 1990.

[7] B. H. Banathy, Systems design of education: A journey to create the future, EnglewoodCliffs, NJ: Educational Technology, 1991.

[8] M. Sashkin and M. G. Sashkin, "Leadership and culture building in school”, California: NcCutchan, 1993.

[9] P. Buhler, "Leaders vs managers", Supervision, 56(5), 24-26, 1995.

[10] F. Crowther, "The William Walker Oration, 1996: Unsung heroes: The leader in our classroom”, Journal of Educational Administration, Vol. 35, No.1, pp. 5-17, 1997.

[11] J. Blase, and J. Blase, Handbook of instructional leadership. How really good principals promote teaching and learning. Thousand Oaks, CA: Corwin, 1998.

[12] G. Fenstermacher and J. Soltis, Approaches to teaching 3rd ed., New York: College, 1998.

[13] P. Hook and A.Vass, "Confident of Teachers Leadership Role", London: Fulton, 2000.

[14] M. Kane, "Leadership requirements and leadership development", 2001. (2016) [Online]. Available: www.execuiteveevolution.com.

[15] L. Lashway, "Developing instructional leaders. ERIC Digest, 160. University of Oregon, Clearinghouse on Educational Management", July, 2002. (2005) [Online]. Available: www.vtaide.com/png/ERIC/DevoIOPing-Instructional-Leaders. Htm

[16] G. Southworth, "Instructional leadership in schools: Reflections and empirical evidence”, School Leadership and Management, Vol. 22, vo. 1, pp. 73-92, 2002.

[17] G.A. YukI, Leadership in organizations, 5th ed., Upper Saddle River. Nr: Prentice, 2002.

[18] D. Sparks, "Interview with Fullan: Change agent", Journal of Staff Development, Vol. 24, No. 1, 2003. [Online] Available: http://www.nsdc.org/library/publications/jsd/fullan241.cfm

[19] Chek Mat, “Leading Skills: Kuala Lumpur: Utusan”, 2003.

[20] L. Lambert, "Leadership refined: An evocative context for teacher leadership”, School Leadership and Management, Vol. 23, No. 4, pp. 421-430, 2003.

[21] M. E. Shippen and S. J. Shippen, "Seven characteristics of affective leaders”, Classroom Ledership, Vol. 7, pp. 1-3, 2004.

[22] J. H. Zenger and J. Folkman, The handbook for leaders: 24 lessons for Extraordinary leadership, New York: McGraw-Hill, 2004.

[23] R. Field, "Leadership in classrooms", 2004. (2016) [Online] Available: www.bus.ualberta.calrfield

[24] S. Wilcox, "Leadership in the classroom”, 2005. (2016) [Online] Available: www.queensu.ca/idc/trainerslhandlleaderlhtml

[25] E. Luaran, "Role of Teachers Leadership Affecting Effectiveness of Teaching and Learning of History In The Classroom Climate", Kuala Lumpur: Universiti Teknologi MARA, 2013. 